\title{
EL CAMPO POLÍTICO EN LOS ESCOLIOS DE NICOLÁS GÓMEZ DÁVILA: COMPILACIÓN SISTEMÁTICA Y COMENTARIOS*
}

\section{RESUMEN}

Comprender el pensamiento político de Don Nicolás Gómez Dávila es definir el campo de producción de su discurso textual. Se presenta una selección de sus escolios en el campo especializado de lo político, pero estructurado en las instituciones jurídicas. Así como el pintor coloca pequeños puntos de color y crea una representación, en el caso de Gómez Dávila quien conocía a la perfección la historia de la pintura francesa, cada punto cromático será un escolio que reunidos en el pensamiento de cada lector, permiten tener un campo epistemológico de la juridicidad, de las instituciones, de la historia y del pensamiento reaccionario, además le permitirán construir una crítica atemporal para la justicia, el marxismo, el revolucionario colombiano entre otros campos de la práctica política.

Palabras Clave: Gómez Dávila, escolio, pensamiento reaccionario.

THE POLITICAL FIELD IN THE GLOSSES OF NICOLÁS GÓMEZ DÁVILA: SYSTEMATIC COMPILATION AND COMMENTS

\section{ABSTRACT}

Understanding the political thought of Don Nicolás Gómez Dávila is to define the field of textual speech production. The author of this paper presents a selection of his glosses in the specialized field of politics, but structured in legal institutions. Just as a painter places small dots of color to depict a scene, in the case of Gómez Dávila, who knew well the history of French painting, each color point can be compared to a gloss that gathered with the rest in the thought of every reader, creates an epistemological framework of the legal, institutional, and historical aspects of the reactionary thought, and allows the reader to build a timeless criticism to Justice, Marxism, and the Colombian revolutionary, among other aspects of political practice.

Keywords: Gómez Dávila, gloss, reactionary thought

\author{
[ GONZALO ORTIZ CHARRY ] \\ Comunicador social-periodista, magister en ciencia \\ política. Docente investigador Facultad de Ciencias \\ de la Comunicación, Uniminuto. E-mail: goortiz国 \\ uniminuto.edu.
}

Es cierto, mis zapatos no puedo hacérmelos yo mismo, pero eso si, señores, no dejaré que nadie me prescriba mi filosofía, los zapatos si que me los mandaré hacer, yo no puedo hacérmelos. ${ }^{1}$

\section{INTRODUCCIÓN}

a investigación partió de una lectura pausada de unos cientos de los escolios gomezdavilianos, la cantidad nunca hará accesible su insurrecto pensamiento, sin embargo en ese periodo de tiempo fue apareciendo, sino el método exacto que es una utopía, si el entramado de la visión fragmentaria y cristalina de un texto implícito que formaba un cuadro textual completo del espíritu de Nicolás Gómez Dávila.

Él había repartido en sus miles de escolios advertencias que a veces parecían obstrucciones a la lectura pero que luego comprenderíamos eran puntos de un cristal perfecto, o en sus palabras eran pinceladas de una pintura puntillista, escuela que se había desprendido del impresionismo francés, pero que formaba en sus puntos de color una realidad poderosa, que configuraba su pensamiento.

Sin embargo había algo más, en la lectura de Gómez Dávila, se mencionan autores de forma sutil y casi de lector

*El presente artículo presenta los resultados de la investigación "El campo político de Nicolás Gómez Dávila" desarrollado durante los años 2012 - 2013 en la Universidad Minuto de Dios, Bogotá

1 Georg Christoph Lichtenberg. (2006). Aforismos [68] Edhasa, Traducción, Introducción y Notas Juan del Solar, Barcelona. 
tímido, es el caso de Burke, pero con una sinceridad escasamente subjetiva menciona los santos de cabecera, Montaigne y Burckhard. Este último, el famoso historiador suizo y rector magnánimo -quien jubila a un filólogo desconocido, Nietzsche-, había escrito en la Introducción a su monumental Historia de la Cultura Griega: "mientras de las cosas de que se ocupa aquella constituyen en su mayor parte una unidad poderosa y simultánea. Se trata de un continuo de proporciones enormes, y lo más adecuado sería exponerlo como se expone una imagen” (Burckhardt, 1964, pág. 13).

El continuo de proporciones hace referencia a los escolios, que en la fragmentariedad que los distingue, sólo están formando un sólido discurso calificado de asistemático, camuflando la imagen de pensador incomprendido y anacrónico, a quien equivocadamente se le descalifica por antimoderno, pedante o el de ser un reaccionario, término que de tanto repetirlo como una mácula termina envileciendo a quien lo utiliza.

He comprendido porqué usa la imagen del cristal, de sus aristas, de la concentricidad del escolio que en un idioma clarísimo llevan al lector descuidado a las mayores estupideces teóricas.

Sin modestia, mi lectura ha encontrado los cristales, esos puntos de pintura puntilliste que vistos en profundad son el campo político del pensamiento reaccionario, y que en su continuum permiten otra visión, si se quiere heterodoxa, de las instituciones políticas actuales.

Más que una investigación o una crítica ad hominen y formalista sobre la obra de un pensador conservador siempre visto como un marginal reaccionario, nuestro trabajo es una metódica, si se quiere brutal, de hacer que los escolios lleguen a más lectores o para acercarlos a los interesados gomezdavilianos que existen sin lugar a dudas.

Si para Gómez Dávila cada escolio es una forma cristalizada de su pensamiento y de sus lecturas inmensas, me he permitido cristalizarlos en un centro único, el del pensamiento reaccionario. Esa sería la punta de diamante en la obra gomezdaviliana. A la manera de orbitas centrípetas, los escolios organizan y hacen hablar al campo político, es decir, a la democracia, al derecho, a la política, al capitalismo, al marxismo, etc.

Creo que sin la referencia breve que hago sobre la Ilustración (Aufklrund) francesa, es imposible comprender el pensamiento del autor conservador, que hace el esfuerzo invaluable de retomar por ejemplo a un Rousseau o a un Burke, junto a toda la historia de la revolución francesa como centros teóricos de una teoría más que antimodernista, una teoría crítica del derecho político y el Estado que subyace en él.
Para este proyecto hemos leído todos los escolios publicados en las ediciones que llamó canónicas, Colcultura, (1977) Procultura (1990) e Instituto Caro y Cuervo (1992). Con alguna paciencia de tejedora hemos logrado un tejido político que se sostiene solo e ingrávido, se sostiene sin mayores discursos y desafueros retóricos. En el proceso se ha puesto una condición leer primero con la lentitud y peligrosidad que tiene cada escolio y luego, cumplida esta parte, sí poder escribir sobre el maestro Nicolás Gómez Dávila.

\section{Gómez Dávila escribía:}

Característica del colombiano imposibilidad de lo concreto, en sus manos todo se vuelve vago; falta de moralidad; la noción de deber es desconocida; la única regla es el miedo del gendarme o del diablo; en su alma ninguna estructura moral, ni intelectual... (Gómes, 2003, pág. 225).

Este mínimo fragmento, de una obra mal valorada, puede suponer la saña y el odio que ganó de una clase intelectual pobre, empoderada y analfabeta la cual no permite todavía valorar en toda su extensión la obra gomezdaviliana.

Sobre su obra fueron usuales las tácticas de la censura, se encuentra el silencio o el uso de adjetivos calificativos abusivos: reaccionario, clerical, aristócrata santafereño, etc. Estas tácticas han bloqueado toda recepción de su obra, y cargan con toda la malignidad del resentimiento nacional.

La obra de Gómez Dávila, que no pasa de ocho libros, soporta el silencio y esparce sus escolios tóxicos. Él había prefigurado lo que le ocurriría luego de muerto, y como es seguro que conquistó el mundo de los escépticos, un heterodoxo en otras palabras, brinda al lector las lecturas que abisman, porque critican su desgraciado mundo que él ironizó con todo el bisturí de un lenguaje preciso, medido y porque no, maldito para lectores que no tuvo en su época y menos ahora cuando el libro es digital, y leer, es un oficio de tinieblas.

Con Gómez Dávila se tiene la fortuna, no de contemplar su biblioteca de miles de libros, sino de leer, alguno de los nueve mil escolios, que manejamos y remiten, de alguna forma, al texto implícito de sus lecturas. Éstas proporcionan a sus lectores un caudal de conocimientos revulsivos que chocan contra nuestras conciencias acríticas y escolásticas.

Así como compró todos sus libros en famosas casas editoriales europeas, en varios idiomas, también se dio el lujo de publicar algunas notas con su propio capital rentístico, que fue heredado y no robado, esto escribiría con ácido humor.

Su aristocracia intelectual la resumió en sus escolios que hieren la razón torpe de todos sus lectores, a los que habita un lector solitario quien amó el cuerpo de la mujer y ali- 
vió en la soledad de sus campos intelectuales la antipatía hacia una modernidad, sosa y boba, como escribe sin muchos adjetivos.

Si lo hemos logrado, nuestra compilación permitirá tener la historia del modo de pensar y de lo que él era capaz, quien se llamaba a sí mismo, el último insurrecto.

Por eso este artículo también está dedicado a mis alumnos que se inician en las llamadas ideas políticas, las instituciones y las nuevas gobernanzas. Soy pesimista en ello, pero sé que existe un lector desconocido que iniciará otras investigaciones más puntuales sobre Don Nicolás Gómez Dávila.

\section{PERFIL DE UN INTELECTUAL OUTSIDER: NICOLÁS GÓMEZ DÁVILA}

Personas de cierta perfección intelectual son contadas en el campo cultural colombiano, no por algún determinismo perverso del medio, la formación de dicha personalidad debe coincidir con una naturaleza especial del sujeto, es verdad, pero ante todo necesita ciertos capitales especiales, sean estos culturales y económicos, y junto a ellos el azar de una enfermedad, como en el caso de un Borges. Y la naturaleza de Don Nicolás Gómez lo lleva a Europa (1920) siendo un niño, donde una educación privada alejada de todo espacio pedagógico lo inicia en otros idiomas, como el francés, el alemán y el inglés.

Esta naturaleza se pone de manifiesto en la ruptura de su lengua nativa, desprendimiento necesario para llegar a ser el hombre universal del Renacimiento como modelo intelectual.

Cuando Gómez Dávila regresa a Bogotá, su país todavía celebraba en forma parroquial su primer centenario de independencia. Bogotá donde nació sigue igual, acaso más tenaz en su ignorancia que en la designación de Atenas Sudamericana, apelativo servil que propuso el diplomático argentino Miguel Cane.

El conocimiento enciclopédico de Gómez Dávila es marginal para un ámbito capitalino, Bogotá. Él sabe, con seguridad, que nunca logrará salir de su vida ascética, bien alejada tanto de la bohemia poética barata de metáforas lúgubres como de algún escritor que emplee morfina como identidad de poeta maldito, al estilo de Baudelaire.

Lo importante de un intelectual no es su biografía anecdótica y encomiástica, sino el modo como aparece en el campo intelectual, y todo aquello que le sirve para llegar a ser un intelectual solitario. Sea porque sí o sea porque sabe que su producción teórica se debe a un pensamiento férreo, que en Gómez Dávila se da, por ser el último reaccionario insurrecto, en un país andino, anal- fabeta y de caciques malones e intelectuales que con una gramática del buen uso del castellano llegan a ser los presidentes gramáticos que copian a diestra y siniestra la gramática de Don Andrés Bello.

Los seudointelectuales bogotanos entenderán el ser reaccionario, como el pensador anticuado y atrabiliario, un insulto personal que hará carrera en Bogotá. Esto provocará que los escolios en su escritura fragmentaria que se escriben contra el burgués, sean tachados primero por el desconcierto y luego por la censura del olvido hasta los primeros años del siglo XXI, donde se inicia la recuperación gomezdaviliana para el canon intelectual universitario.

El hombre escéptico, autor de los escolios con miles de textos implícitos, sabe que posee diversos capitales, unos económicos heredados en bienes materiales y otros capitales simbólicos culturales que adquiere por sus maestros privados y los que acumulará en sus lecturas de los grandes pensadores griegos, latinos, escolásticos y en especial los del siglo XVIII, en las diversas ramas de un capital de saber difícil de calcular.

El intelectual Gómez Dávila podría resultar ser un modelo en la teoría sociológica de Pierre Bordieu, sobre la aparición y la estructura del campo literario, entendiéndose éste como la variedad de géneros intelectuales. Sea el artista, el filósofo y el escritor pertenecen sin diferencias al mismo campo de producción, donde ningún genio increado puede existir. Por eso Gómez Dávila se inventa a sí mismo como intelectual heterodoxo no sólo contra la apertura religiosa católica de su tiempo, también ataca su propia clase, $y$ sin querer queriendo, penetra al campo intelectual que detesta y ahora lo consagra postmorten en palabras de Bordieu:

Para ello, tenía que inventar una figura nueva, la del intelectual, inventando para el artista una misión de subversión profética, inseparablemente intelectual y política, propia para hacer que apareciera como un propósito estético, ético y político, idóneo para agrupar a unos partidarios militantes, todo lo que sus adversarios describían como el efecto de un gusto vulgar o depravado (Bourdieu, 1997, pág. 197).

Don Nicolás Gómez hoy existe entre nosotros y aunque muere en Bogotá a los ochenta y un años (1994) sigue gozando de esplendida salud en sus miles de escolios, notas y textos:

Indiferente a la originalidad de mis ideas, pero celoso de su coherencia, intento trazar aquí un esquema que ordene, con la menor arbitrariedad posible, algunos temas dispersos, y ajenos. Amanuense de siglos, solo compongo un centón [Manta tosca con que se cubrían 
antiguamente las máquinas de guerra] reaccionario (Gómes, 2002, pág. 55).

\section{EL ESTADO DEL ARTE DE LA CRÍTICA A NICOLÁS GÓMEZ DÁVILA}

Si en el campo político como en el juego de tahúres se hacen apuestas desmedidas, "por suerte" en el campo intelectual colombiano, gana la partida el silencio como censura al autor, las trampas para escalar los máximos honores de la academia o la cátedra respectiva hacen del intelectual un agente más comprometido con la burocracia que con su arte.

Esta afirmación se hace realidad en el caso de la obra de Nicolás Gómez Dávila, al principio sumido en la cortina de silencio o a la displicente crítica ad hominen y en la actualidad se recupera en tanto otro personaje del pensamiento nacional, limando sus aristas más peligrosas. El autor marginal del ayer termina como autor de élite y consagración en el canon, quien nace de apuestas difusas a finales del siglo XX y principios del XXI.

Así por las tendenciosas lecturas de algunos intelectuales del siglo XX, que llevan a la incomprensión de un pensador lúcido y peligroso -quien ubicado en una posición de la política de la contra reacción-, será descalificado por antimodernista por unos y hasta simulador por otros.

En la mayoría de los casos las interpretaciones sobre su obra se fundamentan en superficiales formalismos sobre la fragmentariedad de su discurso o el empleo de la forma del escolio.

Maniobras usuales al campo mismo que permiten evitar, por ejemplo la transhistoriedad teórica de Gómez Dávila, que centrada en un arsenal teórico y crítico de peligrosas lecturas, le permitió elaborar una crítica contra la democracia de hoy, a sus agentes políticos o reos especiales que los medios hacen famosos, a los intelectuales y a las reinas de belleza que gozan de su minuto, de una gloria efímera.

Nicolás Gómez Dávila portando el habitus de cristiano pagano ha elaborado la crítica más importante contra el marxismo y sus corifeos, el único colombiano insurrecto reaccionario que heredero de la Aufklarung ${ }^{2}$, el pensamiento reaccionario, interroga la legitimación del presente colombiano sin mencionar los sujetos que han hecho metástasis en la política y en su cultura.

2 la ilustración en Alemania hacia el siglo XVIII
Vemos cómo el incomprendido y manipulado autor aristocrático o hacendado santafereño, como lo califican todavía, subvierte los cánones de nuestra historia intelectual con la escritura escoliastica gomezdaviliana, una de las armas más peligrosas, y si se piensa con rigor, el único arsenal teórico actual.

Nuestro estado del arte no es exhaustivo, apenas una muestra representativa de dislocaciones y aciertos sólo de carácter académico, faltándonos datos de otros municipios y capitales de ultramar.

Aunque es posible que la Revista Mito (1952) del también olvidado Jorge Gaitán Durán, haya publicado algún texto de Gómez Dávila, surge la imposibilidad acceder como usuario del común a la Biblioteca Nacional de Colombia.

Únicamente se encuentran en la Revista ECO- Revista de la Cultura de Occidente- tres trabajos de Gómez Dávila. Este esfuerzo precursor se debe a Don Ernesto Volkening, (1908; 1982) intelectual alemán que publica un fragmento de Textos (1961, pág. 111-126), publicado por el mismo Gómez Dávila,

\section{Las trampas para escalar los máximos honores de la academia o la cátedra respectiva hacen del intelectual un agente más comprometido con la burocracia que con su arte}

que quedó sumergido en el olvido por cuarenta años, hasta la publicación de Villegas Editores en el 2002.

Más tarde la Revista Eco en 1978 (Volkening, 1978, págs. 95-99) y 1979 (Gómes, 1979) publica otros dos textos, el primero presenta anotaciones marginales de Volkening y el segundo presenta una selección de escolios. Es indudable que sólo el silencio insolente cubrió estos textos.

Aunque pueda parecer anecdótico en una compilación de la obra de Don Ernesto Volkening (1998, pág. 1), hay un texto suyo con una dedicatoria a Nicolás Gómez Dávila, prueba de una amistad y no el usual acto de lambonería intelectual.

Pero será hasta el homenaje de la Revista del Colegio Mayor de la Universidad del Rosario (1988), en la que se advertirán algunos adjetivos acertados de Téllez, Mutis, Kaltenbrunner Berd y en especial, la hipótesis de Pizano de Brigard (1988, pág.10) por el misterioso texto implícito, entre otros.

A pesar de la importancia de la revista rosarista que dedica un dossier a Gómez Dávila, y en la que se califica a su ensayo De Iure (1988) [que el autor de los escolios cedió 
a la Revista] mediante el uso de la metáfora de Hernando Téllez "una dura punta de diamante", este ensayo ha pasado desapercibido por los estudiosos de la teoría pura del Derecho, en un país que se aprecia de estudiantes de la política que con una primera demanda a la Corte o al Consejo de Estado, logran anular sentencias, dictando así refinadas jurisprudencias.

Veamos ahora el arte del germanista e hispanista, el maestro Rafael Gutiérrez Girardot quien se convierte en el verdugo de Nicolás Gómez Dávila, y quien con un acto de envidia intelectual, y en su concepto de simulación con el cual ajustició a muchos autores hispanoamericanos de impostura intelectual, él mismo se autoinmola.

Qué pensar de los adjetivos ad hominen que emplea contra Gómez Dávila: "Cachaquito... intimidante rastacuerismo [Aplicase despectivamente al que lleva vida pomposa o presume de culto]... talante seudowildeano... escolios impotentes... autodidactismo... simula ser" (Gutiérrez, 1989, págs. 305-320).

De estos se sirve el profesor boyacense/alemán para demoler el supuesto filosófico de los escolios. Sobra cualquier comentario.

Restando lo publicado en el siglo XXI, me queda una pregunta: porqué "la cultura colombiana" de los intelectuales colombianos, en un momento inicial en palabras del intelectual Rafael Rojas aplica a Gómez Dávila una actitud de: "rechazo visceral a reconocer el legado de opositores públicos” (Rojas, 2006, pág. 16), quien en la actualidad emprende una maniobra de varias jugadas para lograr su aceptación en el panteón de los pensadores colombianos.

\section{LA ESCRITURA FRAGMENTARIA: NICOLÁS GÓMEZ DÁVILA POR SÍ MISMO}

La escolástica académica y valga el pleonasmo, se hubiese ahorrado muchas páginas sobre el formalismo de los escolios o el misterio del texto implícito que subyace en la escritura gomezdaviliana, si de verdad hubiesen leído con cuidado unos cuantos escolios.

Vemos que esta discusión sólo oscurece lo que Gómez Dávila había escrito sobre sí mismo con humor y sobre el porqué de su estilo, por esto hace falta en la discusión haber traído a Blanchot (1969), y a otros grandes semióticos para fundar -como lo hace un profesor-, una nueva ciencia: la escoliástica.

Gómez Dávila tiene la suficiente sagacidad retórica. Manejaba la ironía, y como ningún otro, los valores axiológicos políticos que eran suyos. Apenas escribe lo que debe ser una escritura de su prosa única y ejemplar ante la estu- pidez académica que la califica de una bobería- uno de sus adjetivos que emplea dos o tres veces.

También perseguir un anecdotario y continuar buscando en la soledad de un lector, sólo puede ser la pérdida de tiempo que siempre es una tesis cum laude o la crónica de periódicos domingueros y parroquiales, le sirve para desarmar al cronista o al especialista de tal maniobra.

Él mismo invita a sus pocos lectores a evitar el desatino de una autobiografía, y les dirá, porqué su escritura es fragmentaria, igualmente les evita la pedantería de traer al caso al fundador del aforismo el alemán Georg Lichtenberg y de su admirado Nietzsche ${ }^{i}$.

\section{LA MÁQUUINA ILUSTRADA (AUFKLÄRUNG)}

El vicio del Aufklärung no es la abstracción, es la adhesión ciega y fanática de ciertos postulados que llama "razón" [SE:165].

Que la revolución francesa fuese esencialmente un fenómeno religioso sólo lo vieron con claridad Joseph de Maistre y Michelet [NE:28].

Determinar o fijar una fecha como punto fijo de un cambio determinado en las ideas políticas, o al 14 de julio de 1789 como la inflexión de una institución, que entraba en su punto de quiebre, sería la necia crónica de personajes de un folletín.

La toma de la Bastilla por el pueblo de París es sólo un momento fugaz que se convierte en mito de una revolución triunfante, y que oculta el tormentoso camino que mucho antes habían tomado las ideas políticas, llegará a ser una de las causas decisivas, sino determinantes, en la destrucción de una monarquía eternizada en sus seis siglos de historia.

Es necesario por tanto una digresión y definir el campo político a partir del concepto de los campos sociales:

Los campos sociales no son campos de fuerzas, [a la manera de la física de Newton] sino campos de luchas destinadas a transformar o conservar estos campos de fuerzas. Y la relaciones, ya sea práctica o pensada, que mantienen los agentes [en este caso los Enciclopedistas intelectuales marginales que fuera del campo monárquico] entran al juego de vida o muerte y en contradicción con las clase aristocrática y el alto clero los hace jugar a una transformación política radical (Bourdieu, 1990, pág. 74).

Los campos sociales más diversos como la sociedad de Corte, el campo de los partidos políticos, el de las empresas o el campo universitario, sólo pueden funcionar mientras haya agentes que invierten en los diferentes sentidos de la palabra, que comprometen en ellos su recursos y persiguen 
lo apostado, contribuyendo así por su propio antagonismo conservar la estructura o, en ciertas condiciones, a transformarla.

Las líneas de juego se inician en reconocer, que como agentes políticos, los caballeros Voltaire, Diderot y otros conocen la génesis estructural del Estado monárquico, porque lo han estudiado, o como el señor Montesquieu, han pertenecido a él.

Por otro lado, los ilustrados tienen capitales intelectuales de sobra, y en la ruleta, un lingote de oro como ficha ganadora: la Enciclopedia.

Los ganadores logran cambiar para siempre e instauran un nuevo derecho y una nueva institución que será la democracia moderna, además unos nuevos derechos de los ciudadanos que forman el contenido de la democracia actual.

Es inconcebible comprender la Revolución Francesa sin conocer el movimiento individual de estos agentes políticos, a quienes se les ha llamado con variados adjetivos: Enciclopedistas, philosophes ilustrados (Aufklärung) ${ }^{3}$, aristócratas quebrados y burgueses ${ }^{4}$, periodistas, impresores legales o clandestinos. Son todos ellos quienes fueron armando el arsenal teórico político y filosófico de la revolución burguesa, que llega hasta el día de hoy con la conceptualidad de la democracia, siendo ésta el centro de la política global actual.

Sólo enumerar a estos hombres y su obra principal, nos ubica en el centro del campo intelectual de su época y la cristalización teórico-práctica en la monumental Encyclopidie ou Dictionaire raisonne des sciences, des arts et des metiers (Enciclopedia o Diccionario razonado de las ciencias, las artes y los oficios) (1751-1765). Publicada en 17 volúmenes en la edición original, ésta fue dirigida por Diderot y Dalambert.

1. Francois-Marie Arouet, a quien se le conoce por el apelativo de Voltaire, y se le reconoce como El Padre de la Revolución, colocará las definiciones políticas y religiosas dentro de una racionalidad puntual y satírica por medio de su Diccionario Filosófico (1767).

3 Término que se identifica con la época de las luces, la Ilustración. Como movimiento filosófico del siglo XVIII se caracteriza por la fe en la razón y la solución de los problemas de la humanidad con base en principios racionales (Florian, 2002, pág. 45).

4 El llamado Tercer Estado o Comunes, un compendio de clases estaba formado por diputados una gran mayoría de origen urbano... de los 610 que llegaron a Versalles el 5 de mayo de 1789, un 25\% eran abogados, un 5\% de otras profesiones, un $13 \%$ eran industriales, comerciantes y banqueros, y solo un 7 a un $9 \%$ eran agricultores, de los que solo un puñado eran campesinos (Rude, 1989, pág. 97)
Mencionar alguno de los adjetivos sobre cada uno de ellos, no deja de ser cierto, y muy a la manera de un romántico como Víctor Hugo quien propondrá los siguientes calificativos para Voltaire: Padre de la Revolución. Es la estrella de ese gran mañana. Los sacerdotes tienen razón para llamarlo Lucifer

2. El profesor Chevalier, al referirse al Espíritu de las leyes de Charles Louis Barón de Montesquieu -libro que funda la Teoría política, publicado en 1750 y que vive hasta hoy en las instituciones de toda democracia-, escribe sin contención: “¿Que vasta empresa! ¡Que gran designio. ¡Que amplitud, que majestad en esta concepción! Pero, para realizarla, para pasar a la ejecución, ¡que trabajo sobrehumano! Trabajo para absorber y agotar la vida de un hombre tan dotado como Montesquieu" (Chevalier, 1972, pág. 105).

Montesquieu, pensador político, escribe para la Enciclopedia el artículo sobre el gusto, siendo algo por cierto paradójico, ya que las voces de temas jurídicos y políticos las escribirá el cirujano Jacourt.

3. Jean- Jacques Rousseau, lega para la posteridad $E l$ Contrato Social. Principios de derecho político que sale al público en el año de 1762 .

La importancia de Jean-Jacques Rousseau, el ciudadano ginebrino y el más heterodoxo de los enciclopedistas, presenta una tensión teórica al estar en un arco de posiciones políticas radicales y reaccionarias en el sentido que tendrá el término desde el siglo XVIII.

Escribe María José Villaverde en su clásico prólogo a El Contrato social: "Jean-Jacques encabeza en el XVIII la lista de los enemigos de la propiedad privada capitalista legitimada por Locke" (Villaverde, 1993, s.p.).

La propuesta es contradictoria al establecer un espacio político utópico, con base a un ideal de pequeños propietarios agrarios, igualitario y precapitalista. Que sigue mirando al pasado, que sigue dirigiendo su mirada a la ciudad-Estado grecorromana (Villaverde, 1993).

Así no es sorprendente que nuestro lucido pensador reaccionario Gómez Dávila le dedique un escolio "Rousseau: de la razón a la sensibilidad, de lo general a lo individual, de lo objetivo a lo subjetivo, del valor impersonal al valor personal, del hacer al ser. Celebremos que los demócratas erijan estatuas de ese reaccionario" (Gómes, 1977, pág. 290).

El Contrato será para muchos una utopía contradictoria que parece conducir a un mundo de naturaleza salvaje. El viejo Voltaire, y su envidia personal contra Rousseau, escribe a partir de esta obra que el ginebrino, que se viste con ropas exóticas, sólo desea que el hombre vuelva a caminar en cuatro extremidades. $\mathrm{O}$ en nuestro tiempo, tomando una breve porción de lo escrito por el ginebrino, en El Con- 
trato, "Se les obligará a ser libres" (Rousseau, 1993, pág. 19) como una obligación democrática antagónica, que llevará en esa especie de lenguaje orweliano, la semilla de un totalitarismo con rostro democrático.

Afirmación que ha hecho a los grandes gobernantes del pasado y del presente buscar la cuadratura del círculo político o resaltar -valga el ejemplo con el escudo patria colombiano-, haciendo uso de términos sinónimos: LIBERTAD Y ORDEN.

Sin embargo, esas contradicciones que muchas veces son descontextualizadas, y la mayoría de las veces interléctica empobrecida, hallarán en la teoría roussoniana no sólo una mina de futuros horrores terroristas

Pero El Contrato sigue proporcionando otras perspectivas que van más allá de lo que suelen ser las teorías contractualitas y plantear dos cuestiones fundamentales y actuales: la primera de tipo sociológico que aparece en las primeras páginas "El más fuerte no es, sin embargo, lo bastante para ser siempre el amo, si no convierte su fuerza en derecho y la obediencia en deber" (Rousseau, 1993, pág. 19). pretadas por muchos teóricos de la política desde una dia-

París ordenaron la quema pública de El Emilio, su otra obra, contemporánea de El Contrato.

4. Sobre la obra del Baron de Holbach, Systeme de la nature ou des lois du monde physiqu et du monde moral par M.Mirabaud, secretaire perpetuel et l-un des quarante de l-Academie francaise, que se imprime hacia 1770 (fortuna puesta al servicio de la Enciclopedia), queda en un segundo plano ante el escándalo de publicación. Título idílico por el cual:

La reacción de las instituciones oficiales no se hizo esperar. La Asamblea del Clero de Francia se reúne en abril de 1770, condena la obra y exige al Parlamento que lo haga. En agosto el Canciller Seguier pronuncia la sentencia ante el pleno parlamento que condena a las llamas la "Biblia de los ateos"; no obstante estos jansenistas consideran oportuno hacer públicos algunos fragmentos con el objetivo de escarmentar a los atrevidos escritores que atacan la religión y la estabilidad del Estado (Holbach, 1989, pág. 1).

5. Manuel José Conde de Sieyes (1748-1836), también es el abate Sieyes, y sin embargo "tan poco abate", que según Chevalier es el "Descartes de la política" (1972, pág. 180), publicará en 1789, de forma anónima, ¿Qué es el Tercer Estado? Obra que cierra, de alguna forma, el arsenal teórico que se dispone a tomar el poder e imponer el orden burgués.

El Ancien Regimen o Monarquía absoluta tiene con ésta, más que un

No es gratuito que un autor como Durkheim lo haga fundador de la sociología francesa, y que muchos otros vean en Rousseau un antecedente en la reflexión del poder, la sumisión y los bienes simbólicos de dominación que teoriza Bordieu o Foucault con los biopoderes.

La segunda cuestión toca con la llamada teoría pura del derecho, superando manidos juicios de valor:

Antes de examinar el acto mediante el cual un pueblo elige a un rey, habría que examinar el acto mediante el cual un pueblo se convierte en tal pueblo, porque, siendo este acto necesariamente anterior al otro, es el verdadero fundamento de la sociedad (Rousseau, 1993, pág. 13).

Este sencillo libro tiene la siguiente recepción, en junio de 1762 el Pequeño Consejo de Ginebra decreta que la obra sea quemada por subversiva o terrorista como diríamos hoy, en Francia se persigue a los libreros que difundiesen $E l$ Contrato, y nada menos que la Sorbona y el Parlamento de libro, un panfleto, el tiro de gracia definitivo. La premisa de la teoría de Sieyes es de una fuerza demostrativa sin posible refutación legalista, y menos, militar de la monarquía. El plan de libro, más allá de su análisis sobre las mayorías que representa, del tipo de elección, constitución etc., es una plataforma para la toma de poder: "El plan de este escrito es bastante simple. Tenemos que hacernos tres preguntas: 1. ¿Qué es el Tercer Estado? Todo. 2. ¿Qué ha sido hasta ahora en el orden político? Nada. 3. ¿Qué pide? Llegar a ser algo" (Chevalier, 1972, pág. 180).

Ese algo es el poder, el Tercer Estado es la naciente burguesía y el nuevo sistema económico es el capitalismo.

Tenemos así la formidable máquina social puesta en movimiento, que tiene en lo propuesto por Rousseau una de las primeras aplicaciones en la política:

Se obligará al ciudadano a ser libre, lo que constituye el artificio y el juego de la maquina política, y que hace legítimos los compromisos civiles los cuales, sin ello, serían 
absurdos, tiránicos, y estarían sujetos a los más grandes abusos (Rousseau, 1993, pág. 19). ${ }^{5}$

La máquina teórica de los enciclopedistas teóricos y prácticos inaugura no sólo la metáfora máquina, la hace desembocar en la Revolución Francesa. Es en este momento donde la racionalidad ilimitada se consagra en religión laica, que como el primer motor -según Santo Tomás de Aquino-, posee un movimiento perpetuo que no le permitirá detenerse nunca. Aspiración que la máquina democrática globalizada mimetiza a favor de una economía capitalista. Es la aldea global que penetra todas las dimensiones de la sociedad, sea ésta posmoderna, neoliberal, islámica etc., con la intensidad de sus flujos políticos.

Se utiliza este símil proveniente de la economía, que Deleuze y Guattari incorporan a su teoría del capitalismo esquizofrénico, donde éste no sólo controla y se encarna en flujos de mercancías y capital, ahora se mueve al interior de los seres, de sus flujos deseantes.

La Revolución Francesa apenas nombrada en sus autores más representativos, destruye el código infinito de la monarquía despótica que bloqueaba e imponía sobre los deseos humanos, una censura mediante castigo constantes. Ahora el hombre es libre en sus deseos más perversos y animales, se mueve en una descodificación y desterritorialización operativa constante.

En palabras del ensayista español José Luis Pardo: “Por su parte, las formaciones sociales capitalistas suponen un estado máximo de descodificación de los flujos de deseo, impensable o insoportable para cualquier otra forma social” (1992, pág. 133).

El capitalismo como organización social de estos tiempos globales, no sólo produce mercancías en países periféricos lejanos, produce segundo a segundo -desde el centro, flujos de la producción deseante- al gusto de millones de consumidores insaciables -no sólo de otros derechos del hombre, sino otras formas más aceleradas de existenciapor encontrar un posible paraíso digital más acorde al círculo vicioso del consumo mercantil.

Una mujer ponderada y ajena de la política anecdótica, Ana Arendt, trae una de ellas para significar de forma concluyente lo que en verdad fue la Revolución Francesa:

"La fecha fue la noche del catorce de julio de $1789 \ldots$ cuando Luis XVI se enteró por el duque de La Rochefoucauld- Liancourt de la toma de la Bastilla, la liberación de algunos presos y la defección de las tropas reales ante un ataque del pueblo. El famoso diálogo que se cruzo entre

5 Esta mirada nos remite al siglo XXI, siglo que según Foucault será teorizado por Deleuze el rey y su mensajero es muy breve y revelador. Según se dice, el rey exclamo: " $C$ ' est une revolte, a lo que respondió Liancourt: Non Sire, c' est une revolution” Una revolución que cambiaría el campo político para siempre” (Arend, 1989, pág. 1).

\section{LA MÁQUINA DE LA CONTRAEREACCIÓN}

Se puede afirmar sin ninguna equivocación histórica que sin la Revolución Francesa nunca hubiese existido el pensamiento reaccionario.

Por eso las consecuencias de la Revolución, que el historiador inglés Eric J. Hobsbawm resume con claridad, son determinantes -si se quiere- de la contrareacción iniciada teóricamente en Inglaterra y luego esparcida fuera de Inglaterra:

1. El cambio total del mapa europeo y otras nuevas fronteras, 2. El hundimiento del feudalismo y la instauración de unas nuevas leyes e instituciones, y 3. Una nueva atmósfera política. Ahora se sabía que la revolución en un único país podía ser un fenómeno europeo y que sus doctrinas difundirse más allá de las fronteras (Hobsbawm, 1982, pág. 169).

Chevalier que no brilla por su ironía, exclama en una crítica contra la historia política inglesa: “ Extraña Inglaterra! Ella había dado al continente el ejemplo del deísmo, del ateísmo, del libre pensamiento, de la rebelión contra la autoridad política legitima” (Chevalier, 1972, pág. 180).

Pero también Chevalier olvida o no quiere señalar la crítica precursora del famoso ciudadano ginebrino Rousseau, quien de forma tangencial escribe en El Contrato social o Principios de Derecho político $(1762)^{6}$ una división de la ley que nunca es señalada.

Sin embargo es el irlandés Edmund Burke con su libro Reflexiones sobre la Revolución Francesa (1792), quien inicia la teoría contra el cambio revolucionario francés, a partir de un análisis crítico de la arquitectura de los nuevos Derechos Humanos, y que además lo llevan a una crítica de estos. En esencia la diferencia con el Derecho Consuetudinario inglés que él defenderá como la única posibilidad jurídica basada en un análisis sociológico que documentará,

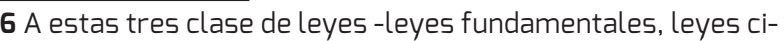
viles, y leyes criminales- se añade una cuarta, que es la más importante de todas, y que no se graba ni sobre mármol ni sobre bronce, sino en el corazón de los ciudadanos: ella es la verdadera constitución del Estado, que cobra todos los días nuevas fuerzas, que, cuando otras leyes envejecen o se apagan, las reanima o las suple, que mantiene en un pueblo el espíritu de sus instituciones, y sustituye insensiblemente la fuerza del hábito o la de la autoridad. Me refiero a la costumbre, a los hábitos (Rousseau, 1993, pág. 54) 
en su libro Reflections (en forma abreviada) que aún hoy es obra esencial y actual de la teoría política.

Así la reacción contra la máquina de la revolución se fundamenta en el terreno de lo que hoy llamaríamos la Teoría Pura del Derecho que se desprende de la crítica religiosa y católica que puede llenar varias bibliotecas (Herrero, 1973). El problema de esta teoría era la superficialidad en una crítica ad hominen y por otra parte el que esté centrada en la teoría del complot universal de la masonería europea, el iluminismo alemán y la desviación jansenista. Crítica que hoy en día se hunde en sus buenas intenciones nada más.

En cambio Burke, sin ser sistemático en su famoso texto -arriba nombrado-, es comprendido ampliamente en un siglo, que parecía hundirse en una revolución, la cual cambiaba toda la estructura jurídica, además era contraria al fundamento y estabilidad de la democracias inglesa y posteriormente a la Norteamericana:

El sentido en el que una Iglesia establecida, una clase particular de orden social y una disposición particular de derechos de propiedad contribuirán a la estabilidad de la opinión pública, una estabilidad que era necesaria para la vida arraigada y civilizada (Hampsher, 1996, pág. 309).

Lo que parece una fina retórica, no lo es, Burke la sustenta con una argumentación celebre que llega a nuestro tiempo y es la dicotomía entre el Principio precedente y el Abstracto ${ }^{7}$. Según esta dicotomia: "el precedente siempre había prevalecido en la práctica jurídica inglesa, nuestro derecho, incluyendo nuestro derecho constitucional, tienen que ser inmemoriales, o, al menos, derivar de modelos siempre más antiguos” (Hampsher, 1996, pág. 311).

Para finalizar seguimos al profesor Fernando Prieto, en síntesis Burke y su pensamiento que hoy es llamado sin sentido reaccionario:

Es algo más que el reflejo de su personal temperamento. Es la forma de expresión de una mentalidad que rehúye lo abstracto, lo general y el sistema, para aplicarse a lo concreto, lo inmediato, lo histórico. Burke cree que el pensamiento abstracto es adecuado para las ciencias, donde el progreso se consigue precisamente a base de analizar y aislar los elementos de los fenómenos... En el mundo de la política el pensamiento a de preceder al revés frente a la abstracción hay que aplicar la concreción; frente al análisis hay que aplicar la síntesis" (Prieto, 1996, pág. 611).

Primero Volpi (2005) y luego el profesor Pachón Soto (2011, págs. 214-215) recalcan la ausencia de un estudio

7 El primero procede del Derecho Consuetudinario, o sea la costumbre y el habitus en la teoría de Bourdieu serio sobre las influencias de los grandes autores reaccionarios sobre Gómez Dávila, es una verdad que falta dilucidar sobre el escoliador bogotano. Sin embargo desde nuestro punto de vista, Gómez Dávila señaló en varios escolios los autores que le permiten hacer un apunte al margen de la obra de ellos, y si se sabe de antemano que todo escolio es una anotación sobre un texto, la tarea no es difícil.

El profesor italiano Franco Volpi señala a Donoso Cortés (1809/1853) como una de las influencias intelectuales del pensador bogotano, que le permite luego -a Pichón Soto-, relacionar a Gómez Dávila con Carl Schmith (1880/1950). La famosa joya del constitucionalismo de la Republica de Weimar, el nacionalsocialismo alemán y su influencia en la academia norteamericana para los modelos antiestatistas del neoliberalismo pasado y presente.

Sin embargo leemos en varios escolios, la crítica de Don Nicolás a todo lo que tuviese que ver con el pensamiento filosófico español. Por eso señala con claridad, no sólo a sus santos patrones del escepticismo y de la historia, anota también los nombres de autores claves del pensamiento reaccionario europeo y especialmente de la literatura francesa que serán el texto implícito de algunos escolios puntuales.

En nuestra selección el más señalado es Edmund Burke, político contemporáneo de la Revolución Francesa, y que -como escribimos antes-, es el primero en escribir contra la Revolución Francesa desde las profundidades del derecho inglés, dejando afuera toda crítica anecdótica sobre el levantamiento francés.

Otros autores del notable siglo XVIII, tan bien alabados por Gómez Dávila, y personajes que en sus obras sostienen una crítica no sólo contra el racionalismo de la época, son católicos ultramontanos y monárquicos, quienes sólo creen en la guerra santa contra todo derecho proclamado por la Revolución Francesa. Son fervientes monárquicos que creen en un derecho sustentado en la costumbre y las divisiones sociales de tipo feudal corporativista, donde no puede existir un Derecho del Hombre igualitario.

Entre los mencionados por Gómez Dávila, a veces en un solo escolio, tenemos a:

José María Conde de Maistre (1754 /1821) noble francés que en su exilio escribe sus famosas memorias históricas Les soires de Saint Peterburg.

Antonio Rivarol (1753 / 1801) periodista e Historiador, Burke lo compara con Tácito, su Pequeño Almanaque de los Grandes Hombres fue un escándalo.

Justus Moser (1720 /1794), escritor y político alemán, admirador de las libertades inglesas que considera la historia como fundamento de la nación, no de los soberanos. 
La reacción como posición política sigue viva todavía en el siglo XXI de aquí la atemporalidad de la crítica en el campo político de Gómez Dávila.

Nuestro reaccionario conservador, sabía muy bien que el pensamiento reaccionario había sido derrotado, pero que sigue entre nosotros con sus inquietudes intactas, y en lo que nos concierne, su crítica es la más certera contra las instituciones políticas y sus formas unidimensionales de dominación ${ }^{\text {ii }}$.

\section{SELECCIÓN DE ESCOLIOS SOBRE MARXISMO, TEORÍA Y CORIFEOS.}

Nicolás Gómez Dávila ha leído muy bien al joven Marx y en alguna carta de Marx maduro en la que niega que él sea marxista. Por eso el aristócrata sabanero sabía que los corifeos del marxismo, que tuvo la Bogotá de su tiempo, fueron el ejemplo perfecto de lo que sería la escolástica soviética. Los manuales de la Editorial Progreso de Moscú y la deriva lógica hacia la revolución que nunca llegó, dejó en la historia colombiana la conducta del revolucionario henchido de confusión, espuria clandestinidad y citomaníaco de los textos soviéticos, o aún peor, sus revistas que anunciaban la existencia del paraíso proletario. Estaban lejos de sospechar de su Nomeklatura zarista roja y policíaca.

Nunca había existido en nuestro país una crítica donde la cristalización de un pensamiento reaccionario dispare, con tino fijo, al corazón de los falsos revolucionarios, agentes de un aparato ideológico hermano de la propia burguesía ${ }^{\mathrm{iii}}$.

\section{CONCLUSIÓN ABIERTA CON FINAL}

Un lector perspicaz luego de leer centenares de escolios pronto se da cuenta que lo que subyace en ellos es una transparente estructuración de la historia, y de un campo político criticado a la, manera de un pensador solitario e insurrecto.

Los problemas o trampas de todo discurso fragmentario como el de Don Nicolás Gómez Dávila sin la suficiente preparación intelectual ilustrada en las grandes obras que surcan las lecturas de nuestro autor. Gómez Dávila, solo permiten inicialmente una recepción metafórica, que toman como cosa los benditos escolios, refiriéndose a la cristalografía o la metalurgia, punta de diamante etc., que nos recuerdan una famosa metáfora de la Yourcenar ${ }^{8}:$ “... reconocí las extrañas escorias y las concreciones inesperadas de la materia que ha pasado por las llamas” (Yourcenar, 1986, pág. 188), la gran académica francesa

8 YOURCENAR, Marguerite, (1986-188) ¿QQuién no tiene su minotauro? Teatro III, Editorial Lumen, Barcelo se acerca a lo que significa la estructura de cada escolio gomezdaviliano.

Las anteriores afirmaciones pueden llevar a una dicotomía perversa, sustentada en un yo lector que determina al autor desde su origen de clase y capitales económicos (críitica de Gutiérrez Girardot y compañía) lectura de una ideología que se dice política pero en jerga sólo es mamerta refractaria y refleja, con los resultados conocidos de la crítica literaria colombo-vaticana.

La segunda forma es fijar la lectura en un estrecho formalismo abstracto y ajeno a toda comprensión. Este corto circuito paralizante selo pudo romperse con la teoría del campo literario y las condiciones de un habitus propio de los sujetos, en la teoría de Pierre Bourdeu.

Dada esta situación ubicamos el campo literario y el solapamiento de éste con el campo político para ver el habitus o sea el pensamiento de Gómez Dávila hecho historia y cuerpo.

La lectura de los escolios precipita a lo que subyace en ellos, una transparente estructuración de sus lecturas. La sinceridad histórica la vemos cuando el autor ese cachaquito como lo califica Gutiérrez Girardot, cita en uno de sus escolios a sus santos de devoción, callando que los leyó o los nombra por simular alguna sabiduría histórica.

Mencionar a Montaigne y Burkardt en un país remoto como Colombia sigue siendo todavía un atropello a la razón escolástica de sus mandarines inquisitoriales.

No dudamos que Gómez Dávila leyó los varios tomos del rector emérito de la muy antigua Universidad de Basilea Historia de la Cultura Griega y los Ensayos eternos del Señor de la Montaña como le decía Don Francisco de Quevedo al gran ensayista francés.

Mi lectura y selección de los escolios en campos institucionales, sólo es un boceto de la configuración del pensamiento inagotable e intemporal de Don Nicolás Gómez Dávila.

Lo mismo hubiésemos podido hacer alrededor de Gómez Dávila y sus escolios sobre la erótica que como escribe Franco Volpi "su metafísica sensual...capaz de salvar, la riqueza densa y sensual del mundo” (2003, pág. 21).

Nuestra primera lectura es el inicio de una deriva a otras, que como profesor dedicado a señalar lecturas muchas veces estériles, solo cree con el profesor Volpi el deseo de que "Algún día, quizás, toda la inteligencia llegue a ser gomezdaviliana” (2003, pág. 39). 


\section{BIBLIOGRAFÍA}

Arend, H. (1989). Sobre la revolución en libertad y terror. La revolución francesa en imágenes y textos. . Medellín: Universidad de Antioquia, Instituto de estudios políticos.

Blanchot, M. (1969). Nietzsche y la escritura fragmentaria. Revista ECO, XIX, 5-7.

Bourdieu, P. (1990). Clase inaugural, Cátedra de sociología del Colegio de Francia, Sociología y Cultura. México D.F.: Grijalbo.

Bourdieu, P. (1997). Las reglas del arte. Génesis y estructura del campo literario $\left(2^{a} E d\right)$. Barcelona: Anagrama.

Burckhardt, J. (1964). Historia de la cultura griega. Barcelona: Iberia.

Chevalier, J.-J. (1972). Los grandes textos políticos. Madrid: Aguilar.

Di Filipo, M. (1983). Lexicón de colombianismos. Bogotá: Banco de la Republica.

Florian, V. (2002). Diccionario de filosofía. Bogotá: Panamericana.

Gómes Dávila, N. (1977). Escolios a un texto implícito. Bogotá: Instituto Colombiano de Cultura.

Gómes Dávila, N. (1979). Escolios a un texto implícito, II parte. Revista ECO, 210.

Gómes Dávila, N. (1988). De iure. Revista del Colegio Mayor de Nuestra Señora del Rosario(542), 67-85.

Gómes Dávila, N. (1992). Sucesivos escolios a un texto implícito. Bogotá: Instituto Caro y Cuervo.

Gómes Dávila, N. (2002). Textos I y II . Bogotá: Villegas editores.

Gómes Dávila, N. (2003). Notas (2 Ed.). Bogotá: Villegas editores.

Gutiérrez, R. (1989). Colombia: un caso complejo . Bogotá: Temis.

Hampsher, I. (1996). Edmund Burke. Historia del pensamiento político moderno. Madrid: Editorial Ariel.

Herrero, J. (1973). Los orígenes del pensamiento reaccionario español. Madrid: Cuadernos para el Dialogo.

Hobsbawm, E. (1982). Las Revoluciones burguesas. Madrid: Punto Omega.

Holbach, B. D. (Sistema de la Naturaleza. Prólogo). 1989. La Habana: Editorial de Ciencias Sociales.

Pachón, D. (2011). Nicolás Gomes Dávila, un exiliado de la modernidad. Bogotá: Ediciones desde abajo.
Pardo, J. L. (1992). Deleuze: violentar el pensamiento. Bogotá: Cincel.

Pizano, F. (Abril/Mayo de 1988). Semblanza de un colombiano. Revista del Colegio Mayor de Nuestra Señora del Rosario(8).

Prieto, F. (1996). Manual de historia de las teorías políticas. Madrid: Unión Editorial.

Rojas, R. (2006). Tumbas sin sosiego. Barcelona: Anagrama.

Rousseau, J.-J. (1993). El Contrato Social. Madrid: Atalaya.

Rude, G. (1989). La Europa Revolucionaria: 1783- 1815. En F. de Bedout Gaviria, Libertad y Terror. La Revolución Francesa en Imágenes y Textos. Medellín: Universidad de Antioquia.

Villaverde, M. (1993). Estudio Preliminar a El Contrato Social. Madrid: Altaya.

Volkening, E. (1961). Textos. Revista ECO, III(2).

Volkening, E. (1978). Anotado al margen de El Reaccionario de Nicolás Gómez Dávila. Revista ECO(205).

Volkening, E. (1998). Evocación de una sombra. Bogotá: Planeta Colombiana Editorial.

Volpi, F. (2005). El solitario de Dios. Bogotá: Villegas Editores.

(2003). "Una voz inconfundible y pura".

En NOTAS, Nicolás Gómez Dávila, Villegas Editores, Bogotá.

Voltaire. (1986). El siglo de Luis XIV. Barcelona: Ediciones Orbis.

Yourcenar, M. (1986). Quién no tiene su minotauro? Teatro III, Editorial Lumen, Barcelona.

\section{Notas}

i El lector no encontrará aforismos en estas páginas. Mis breves frases son los toques cromáticos de una composición puntilliste. [ E:11]

- La prosa se corrompe cuando se propone, en lugar de ser simplemente inteligible, ser convincente.

- Debemos decir sin esguinces lo que pensamos, pero dejar que el lector se convenza solo. [E2:38]

- No he pretendido el rigor de una doctrina, sino la flexibilidad de una actitud.[E2:351]

- Lo que aquí digo parecerá trivial a quien ignore todo a lo que aludo.[E2:411] 
- Dudaría más de la calidad de estas páginas si no supiera quiénes hallarán aquí el repertorio de las opiniones que abominan.[E2:500]

- Para impedir que el vulgo lo profane le basta al libro el hermetismo de una prosa sencilla, inteligente y clara. [E2:429]

- Escribir bien consiste en describir una curva mediante el menor número de tangentes. [NE:79]

- El texto que admita paráfrasis es subalterno.[NE:123]

- Pongamos en cuarentena toda interpretación de un texto que no provenga de una impresión global. Siempre hay citas para las adulteraciones.[NE:125]

- La literatura no es droga psicológica, sino lenguaje complejo para decir cosas complejas. Un texto melodramático o cacofónico, además de feo, es falso.[NE:129]

- El viaje por el texto claro de una inteligencia lúcida es el único placer perfecto.[NE:135]

- La verdadera elegancia verbal envaina la espada antes que el adversario sienta la estocada que lo mató.[NE2:6]

- Los argumentos capaces de convencer a nuestros contemporáneos tienen mal sabor, mal olor, mal color. [NE2:24]

- Perfeccionemos la insolencia de nuestras ideas. [NE2:65]

- El fragmento es el medio de expresión del que aprendió que el hombre vive entre fragmentos.[NE2:87]

- Acusar el aforismo de no expresar sino parte de la verdad equivale a suponer que el discurso prolijo puede expresarla toda.[NE2:122]

- Canónigo obscurantista del viejo capítulo metropolitano de Santa Fe, agria beata bogotana, rudo hacendado sabanero, somos de la misma ralea.

- Con mis actuales compatriotas sólo comparto pasaporte.[NE2:135]

- El vulgo trata con acertada discreción al escritor ilustre; celebra su nombre e ignora sus libros.[NE2:167]

- El discurso continuo tiende a ocultar las rupturas del ser.

- El fragmento es expresión del pensamiento honrado. [NE2:203]

- Todo acontecimiento, además de existir como texto en un contexto, se proyecta en un supra-texto. [E:123]

\section{ii Selección de escolios sobre el pensamiento reaccionario}

- La legislación que protege minuciosamente la libertad estrangula las libertades. [E:30]
- Los aspirantes a una civilización racional premeditan degollinas.[E:30]

- La presencia política de la muchedumbre culmina siempre en un Apocalipsis infernal. [E:31]

- El Renacimiento, el Aufklarung, y la Tecnocracia, son hijos indiscutibles del cristianismo.

- Hijos crecientemente siniestros que engendra en las esperanzas cristianas el olvido del pecado original. [E:65]

- Un solo tipo de sociedad tuvo un contrato social por raíz histórica y por soporte ético: el feudalismo. [E:130]

- El reaccionario es el instigador de esa radical insurrección contra la sociedad moderna que la izquierda predica, pero cuidadosamente elude en sus farsas revolucionarias. [E:154]

- Si bien Joseph de Maistre afirma que el demonio tan sólo destruye, la historia posterior demuestra que también construye. [E:158]

- La providencia resolvió entregar al demócrata la victoria $\mathrm{y}$ al reaccionario la verdad. [E:161]

- El pasado que el reaccionario encomia no es época histórica, sino norma concreta.

- Lo que el reaccionario admira en otros siglos no es su realidad siempre miserable, sino la norma peculiar a que desobedecían. [E:162]

- El moderno no desoye al reaccionario porque sus reparos le parezcan impropios, sino porque no le son inteligibles. [E:162]

- El conservatismo de Burke no es un "irracionalismo" que se enfrenta al "racionalismo” contemporáneo, sino frente al Aufklärung, que llama principios sus prejuicios, el acta de independencia de la razón experimental. [E:191]

- Sólo un régimen monárquico puede ser constitucional.

- Donde la sociedad se gobierna a sí misma, o donde gobierna un autócrata, la constitución carece de guardián que la defienda de caprichos electorales o de caprichos cesáreos.

- Sólo donde el pacto entre gobernantes y gobernados descansa sobre la recíproca desconfianza de las partes, tanto la obediencia del súbdito como la soberanía del príncipe tienen fronteras guarnecidas. [E:230]

- La historia de la filosofía se ordena en torno a dos reacciones victoriosas: Platón y Kant. [E:276]

- Rousseau: de la razón a la sensibilidad, de lo general a lo individual, de lo objetivo a lo subjetivo, del valor impersonal al valor personal, del hacer al ser. 
- Celebremos que los demócratas erijan estatuas de ese reaccionario. [E:290]

- Más que cristiano, quizá soy un pagano que cree en Cristo. [E:316]

- La revolución francesa parece admirable a quien la conoce mal, terrible a quien la conoce mejor, grotesca a quien la conoce bien. [E:349]

- Las fiestas democráticas conmemoran motines victoriosos. La aristocracia prefería las pompas litúrgicas.

- La fiesta de la Federación terminó en bailes de barrio. La etiqueta imperial se prolongó en el rito galicano de una misa milanesa. [E:352]

- "Une nouvelle distribution de la richesse produit une nouvelle distribution du pouvoir" escribe Barnave en 1785 .

- Ley que cumple la Revolución Francesa.

- Pero las reformas electorales y las revoluciones posteriores cumplen una ley distinta: Une nouvelle distribution du pouvoir produit une nouvelle distribution de la richesse.

- Las "leyes históricas" tienen corta vigencia. [E:370]

- El reaccionario inventó el diálogo al observar la desemejanza de los hombres y la variedad de sus propósitos.

- El demócrata practica el monologo, porque la humanidad se expresa por su boca. [E:403]

- Conviene, sin duda, insultar al reaccionario notorio (renegado de los Whigs - lost leader - foliculario de la Santa Alianza -burgués amedrentado por la Communeetc., etc.), pero más vale callar la lista de los reaccionarios cautos si no queremos resquebrajar las convicciones del demócrata. [E:441]

- El reaccionario simpatiza con el revolucionario de hoy, porque lo venga del de ayer. [E:442]

- El pensamiento democrático acostumbra deducir las consecuencias del hecho con la misma confianza rectilínea que las implicaciones de un principio.

- Lo que el reaccionario, en cambio, sabe ver es de índole paradójica de los hechos, de los hombres, del mundo. [E:443]

- Frente a un pensamiento adverso, el pensamiento reaccionario no se paraliza en un rechazo indignado.

- Intenta, a la inversa, asimilarlo, sabiéndose capaz de nutrirse de jugos venenosos. [E:447]

- Sólo respeto la declaración enfática henchida de interrogaciones clandestinas. [E:447]

- El reaccionario, hoy, es meramente un pasajero que naufraga con dignidad.[E:449]
- El que radicalmente discrepa no puede argüir, sino enunciar.

- La época de argumentar feneció para el que rechaza los postulados modernos.

- No compartiendo convicciones con nuestros contemporáneos, podemos ambicionar convertirlos, pero no convencerlos.

- Al reaccionario sólo le es dable proferir sentencias abruptas que se le indigesten al lector. [E:476]

- Sólo un talento evidente hace que le perdonen sus ideas al reaccionario, mientras que las ideas del izquierdista hacen que le perdonen su falta de talento. [E2/6]

- Las obras de Sade son los apéndices clandestinos de la Encyclopédie. [E2/26]

- Nada tan preciso como un cólico repentino para evacuar la retórica del que perora patéticamente sobre la "dignidad del hombre”. [E2:26]

- La primera revolución estalló cuando se le ocurrió a algún tonto que el derecho se podía inventar. [E2:164]

- El feudalismo se fundó sobre sentimientos nobles; lealtad, protección, servicio.

- Los demás sistemas políticos se fundan sobre sentimientos viles: egoísmo, codicia, envidia, cobardía. [E2:96]

- Las burocracias no suceden casualmente a las revoluciones.

- Las revoluciones son los partos sangrientos de las burocracias. [E2:98]

- La esencia de la propiedad es la unión indisoluble de una familia y de una tierra.

- El resto consiste en posesiones equívocas y desmoralizadoras. [E2:122]

- Para ser revolucionario se requiere ser algo bobo, para ser conservador algo cínico. [E2:128]

- Nietzsche es el paradigma del reaccionario que claudica, adoptando las armas del enemigo, porque no se resigna a la derrota. [E2:150]

- Ser reaccionario no es creer en determinadas soluciones, sino tener un sentido agudo de la complejidad de los problemas. [E2:166]

- Hegel, ¿"Filósofo del Estado Prusiano"? - ¿"Filósofo de la Revolución Francesa”?

- ¡Como si toda "revolución francesa” no acabara en "estado prusiano”. [E2:183]

- Al demócrata, para refutar los argumentos del reaccionario, sólo se le ocurre decir que son argumentos de reaccionario. [E2:249] 
- El pensamiento reaccionario ha sido acusado de irracionalismo porque se niega a sacrificar los cánones de la razón a los perjuicios del día. [E2:253]

- La actitud reaccionaria sería hoy una inocentada, al pretendiese más que atrincherarse en la objetividad del valor. [E2:270]

- Mientras que una máquina podría deducir cabalmente las consecuencias de los principios democráticos, para deducir las de los principios reaccionarios se requieren inteligencias cautelosas, alertas, sutiles. [E2: 270]

- De los "derechos del hombre" el liberalismo moderno ya no defiende sino el derecho al consumo. [E2:409]

- El reaccionario tiene que acostumbrarse a vivir en un lívido crepúsculo de derrota. [E2:432]

- $\mathrm{Al}$ izquierdista que proteste igualmente contra crímenes de derecha o de izquierda, sus camaradas, con razón, le dicen reaccionario.[E2:496]

- El reaccionario no redacta la defensa de un vago "antiguo régimen”; reseña a la víctima, para instruir mejor el expediente de la revolución. [NE:97]

- El pensamiento reaccionario irrumpe en la historia como grito monitorio de la libertad concreta. Como espasmo de angustia ante el despotismo ilimitado a que llega el que se embriaga de libertad abstracta. [NE: 97]

- Comenzando con Moser, Rivarol, Burke, cuando un reaccionario condena, la historia rara vez no ejecuta la sentencia. [NE:106]

- Los lectores del escritor reaccionario jamás saben si conviene aplaudirlo con entusiasmo o patearlo con rabia. [NE:138]

- El reaccionario auténtico no parte de ideas políticas reaccionarias.

- A veces llega a ellas.[NE:182]

- El Orfismo y Rousseau ocupan en la historia una posición semejante.

- Sí ambos, por una parte, impulsaron el movimiento democrático y la religiosidad gnóstica, ambos, por otra, propiciaron el sentimiento religioso y la actitud reaccionaria.

- Difícil explicar a Burke sin el clima rousseauniano o a Platón sin el clima órfico. [NE2:10]

- El más convencido de los reaccionarios es el revolucionario arrepentido, es decir; el que ha conocido la realidad de los problemas y ha descubierto la falsedad de las soluciones. [NE2:25]

- Los reaccionarios somos infortunados: la izquierda nos roba ideas y la derecha vocabulario. [NE2:29]
- Para transformar la idea de "contrato social" en tesis eminentemente democrática se necesita el sofisma del sufragio.

- Donde se suponga, en efecto, que la mayoría equivale a la totalidad, la idea de consenso se adultera en coerción totalitaria. [NE2:91]

- $\mathrm{Al}$ someter las categorías del derecho consuetudinario medieval a las categorías del derecho cesariano, los glosadores comenzaron a forjar el Estado.

- Un Merlin es el sucesor de un Dubois que es el sucesor de un Accursius. [NE2:92]

- Para corromper al individuo basta enseñarle a llamar derechos sus anhelos personales y abusos los derechos ajenos. [NE2:102]

- De civilización sólo se puede hablar donde el zapatero profesional, verbi gratia, no es un traficante en zapatos sino un apasionado de zapatería. [NE2:121]

- La prescripción es la única fuente real de derecho. [NE2:165]

- Contra la prescripción no vale jurídicamente sino la continuidad de la protesta. [NE2:165]

- La prescripción es la protocolización del consenso; el consenso es la realidad empírica del convenio; el convenio es el esquema jurídico del derecho. [NE2:165]

- Al reaccionario nunca lo juzgan por lo que dice, sino por lo que suponen que dijo. [NE2:212]

- Los reaccionarios les procuramos a los bobos el placer de sentirse atrevidos pensadores de vanguardia. [SE:16]

- Los textos reaccionarios les parecen obsoletos a los contemporáneos y de una actualidad sorprendente a la posteridad. [SE:23]

- El reaccionario no es un pensador excéntrico, sino pensador insobornable. [SE:38]

- La raíz del pensamiento reaccionario no es la desconfianza en la razón, sino la desconfianza en la voluntad. [SE:40]

- Ni declaración de derechos humanos, ni proclamación de constituciones, mi apelación a un derecho natural, protegen contra la arbitrariedad del estado.

- Sólo es barrera al despotismo el derecho consuetudinario. [SE:73]

- No es en textos modernos en donde hay que buscar las fuentes de los "derechos del hombre", es en el connubio de la cristiandad con el feudalismo. [SE:101]

- Lo que el reaccionario le niega al Aufklarung no es que haya principios universalmente válidos, sino que los 
principios que el Aufklarung proclama hagan parte de esos principios. [SE:115]

- Burke pudo ser conservador. Los progresos del "progreso" obligan a ser reaccionario. [SE:126]

- Después de haber sido, en el siglo pasado, el instrumento del radicalismo político, el sufragio universal se está convirtiendo, como lo previó Tocqueville, en mecanismo conservador. [SE:144]

- Donde no sea consuetudinario, el derecho se convierte fácilmente en simple arma política. [SE:154]

- La reacción no es más que la traducción en lenguaje realista de los principios de un Constant, un Humboldt, un Mill, un Tocqueville. [SE:171]

\section{iii Selección de escolios sobre marxismo, teoría y corifeos.}

- La estructura de una sociedad, o de una época, depende de una opción, de una actitud axiológica.

- Una interpretación económica solo es científica cuando el fundamento axiológico de una estructura es económico.

- El marxismo volvió método una observación exacta pero históricamente circunscrita. [E: 61]

- Marx alista al servicio del proletariado las acusaciones a la sociedad burguesa formuladas por los escritores reaccionarios. [E:86]

- Todo marxista disfruta de dos marxismos: el marxismo corriente que predica y el marxismo esotérico con el cual refuta las críticas al primero.

- Por lo demás, existe un tercer marxismo: el que despectivamente el marxista atribuye a sus interlocutores bajo el nombre de marxismo vulgar. [E:167]

- Un léxico de diez palabras basta al marxista para explicar la historia. [E:199]

- Dos seres inspiran hoy particular conmiseración: el político burgués que la historia pacientemente acorrala y el filósofo marxista que la historia pacientemente refuta. [E:208]

- Las clases sociales tienen origen estructural, no histórico.

- La clase resulta de la interacción social, como el valor resulta de la interacción económica. La clase es elemento estructural de la sociedad, como el capital de la economía.

- La sociedad sin clases de Marx remeda la economía sin capital de sus predecesores ingenuos. [E:229]
- El marxismo sólo descansará cuando transforme campesinos y obreros en oficinistas pequeño-burgueses. [E:230]

- Como Marx evidentemente dice que las fuerzas de producción de una sociedad determinan finalmente su estructura, y como, por otra parte, las fuerzas de producción de la actual sociedad comunista y de la actual sociedad capitalista son evidentemente las mismas, Marx propiamente enseña que la diferencia entre capitalismo y comunismo sólo puede consistir en la diferencia pasajera entre algunos de sus aspectos jurídicos.

- La sociedad industrial comunista y la sociedad industrial capitalista aplastan al hombre bajo el mismo peso. [E:250]

- Tácitamente seguro de asentarse en la síntesis, Marx anuncia una dialéctica de la historia y escribe una teodicea. [E:263]

- Olvidando el proceso histórico en que "Razón”, "Libertad", "Progreso", se engendran, sin analizar el significado ideológico que tienen, concediéndoles el privilegio de una atemporalidad misteriosa, Marx se rinde incondicionalmente a los ideales del radicalismo burgués. [E:289]

- Ante el hombre inteligente que se vuelve marxista sentimos lo mismo que el incrédulo ante la niña bonita que entra al convento. [E:344]

- El marxismo enseña que la economía determina la historia, pero pretende redimir al hombre con una reforma jurídica. [E:354]

- La ambigüedad de la noción de clase permite adulterar la historia, transformando las guerras civiles, que son frecuentes, en guerras serviles, que son escasas. [E:355]

- La energía de los epítetos revolucionarios de un conventículo de intelectuales burgueses supera la energía de todas las revoluciones de la historia. [E:394]

- Los izquierdistas no son los representantes de los pobres, sino los delegados de las ideas pobres. [E:439]

- Derrotado en campo raso, el marxista, para salvarse, se desliza en la fortaleza hegeliana por el portillo que le franquean los manuscritos juveniles de Marx. [E:453]

- Las revoluciones no son hijas de pobres envidiosos o famélicos, sino de ricos pusilánimes o ambiciosos. [E2:40]

- La revolución - toda revolución, la revolución en sí- es la matriz de las burguesías. [E2:63]

- Las burocracias no suceden casualmente a las revoluciones. Las revoluciones son los partos sangrientos de las burocracias. [E2:98] 
- El historiador marxista, para mayor tranquilidad, debe omitir cautelosamente de su bibliografía los libros del historiador serio. [E2:101]

- La escolástica marxista llegó, de un solo paso, al siglo XV. [E2:120]

- Para ser revolucionario se requiere ser algo bobo, para ser conservador algo cínico. [E2:128]

- Un "socialismo con cara humana" es un aguardiente sin alcohol. [E2:162]

- Los partidarios de la sociedad igualitaria suelen ser siempre chiquitos. [E2:186]

- El mal humor es secreción específica del intelecto de izquierda. [E2:211]

- El ironista de izquierda inquieta por la dureza de sus pupilas y la longitud de sus colmillos. [E2:211]

- Las ideologías se inventaron para que pueda opinar el que no piensa. [E2:227]

- Los actuales textos marxistas tendrán, en la historia del pensamiento moderno, tanta importancia como las summulae de los canonistas romanos del XVIII. [E2:262]

- Los pronósticos de Marx fallaron, los de Burke se cumplieron.Por eso unos pocos leen a Burke y media humanidad venera a Marx. [E2:281]

- Llamase comunista al que lucha para que el estado le asegure una existencia burguesa. [E2:330]

- Las revoluciones se columpian entre el puritanismo y la crápula, sin rozar el suelo civilizado. [E2:335]

- Revolución es el período durante el cual se estila llamar "idealistas" los actos que castiga todo código penal. [E2:335]

- Varias tesis marxistas parecen atribuciones apócrifas de adversarios deshonestos. [E2:349]

- Ser marxista parece consistir en eximir de la interpretación marxista las sociedades comunistas. [E2:349]

- El marxismo cae sobre la inteligencia, como una lluvia gris de cenizas volcánicas sobre una tierra labrantía. [E2:404]

- Las escisiones ideológicas se presentan en los partidos de izquierda cada vez que la oligarquía del partido no cede los cargos lucrativos a un nuevo grupo de aspirantes.

- La dialéctica del pensamiento de izquierda tiene por resorte la ambición de ascenso burocrático. [E2:439].

- Las revoluciones no resuelven más problema que el problema económico de sus jefes. [E2:440]

- Los jóvenes no son necesariamente revolucionarios sino necesariamente dogmáticos. [E2:447]

- La mentira es la musa de las revoluciones; inspira sus programas, sus proclamaciones, sus panegíricos. Pero olvida amordazar a sus testigos. [NE:19]

- Una cándida imagen del pueblo alienta la polémica antiburguesa del socialismo. En la emancipación burguesa florecen los vicios latentes del pueblo. [NE: 31]

- El pintoresco traje de revolucionario se descolora insensiblemente en severo uniforme de policía. [NE:81]

- Reaccionarios y marxistas viviremos igualmente incómodos en la sociedad futura; pero los marxistas mirarán con ojos de padre estupefacto, nosotros con ironía de forastero. [NE:81]

- El aburguesamiento del proletariado es la prueba de su definitiva incorporación en la izquierda. [NE:85]

- El izquierdista escribe con hiel disuelta en babas. [NE:85]

- El marxismo se desdibuja al reflejarse en la mente gelatinosa del izquierdista. [NE:162]

- La historia no le ha dejado intacto al marxismo sino el vocabulario. [NE:167]

- Hay doctrinas, como el hegelianismo a mediados del siglo XIX y el marxismo a principios de éste, que no fecundan sino al descomponerse. [NE:196]

- El más convencido de los reaccionarios es el revolucionario arrepentido, es decir; el que ha conocido la realidad de los problemas y ha descubierto la falsedad de las soluciones. [NE2:25]

- El marxismo fue la última ideología honesta del optimismo burgués. [NE2:83]

- Marx no es profeta hebreo, sino ideólogo burgués.

- No lo inspira un mesianismo hereditario, lo inspira el optimismo de la burguesía triunfante de su tiempo. [NE2:83]

- El marxismo es la teología puritana de la religión burguesa. [NE2:83]

- Si la izquierda sigue adaptando, una tras otra, las objeciones que los reaccionarios le tempos hecho al mundo moderno tendremos que volvernos izquierdistas. [NE2:101]

- La prosa del izquierdista es siempre electoral. [NE2:119]

- El socialismo se vale de la codicia y la miseria; el capitalismo se vale de la codicia y de los vicios. [NE2:153]

- El marxismo petrifica la inteligencia que toca. [NE2:188] 
- La plúmbea prosa del marxista ejerce una atracción irresistible sobre las mentes plomizas. [NE2:190]

- La mente del marxista se fosiliza con el tiempo; la del izquierdista se vuelve esponjosa y blanda. [SE:12]

- En el estado moderno las clases con intereses opuestos no son tanto la burguesía y el proletariado como la clase que paga impuestos y la clase que de ellos vive. [SE:43]

- Erudición y experiencia son los dos adversarios invencibles de la izquierda. [SE:70]

- La falsificación del pasado es la manera como la izquierda ha pretendido elaborar el futuro.[SE:70]

- La izquierda no es vulnerable sino después de sus triunfos. [SE:71]

- La primera historia que el marxismo no entiende es su propia historia. [SE:105]

- El izquierdista no tiene opiniones sino dogmas. [SE:109]

- Comparadas a la estructura sofisticada de todo hecho histórico, las generalizaciones del marxismo son de una ingenuidad enternecedora. [SE:159]

- Salvo en los primeros momentos de entusiasmo revolucionario, la mayoría de la población, en todo país y en toda época, pertenecen a un centro-derecha. [SE:179] 